\title{
Glycemic Control and its Predictors among Diabetic Patients Attending a Tertiary Hospital: A Retrospective Observational Study
}

\author{
Ya'u Adamu ${ }^{1,2,3}$, Khalid M. Garba ${ }^{1,4}$, Shamsudeen $\mathrm{YAU}^{5}$, and \\ Jamilu Ya'u",6

\footnotetext{
${ }^{1}$ Faculty of Pharmaceutical Sciences, Bayero University Kano, Nigeria

${ }^{2}$ Faculty of Pharmaceutical Sciences, Naresuan University, Phitsanulok, Thailand

${ }^{3}$ Department of Epidemiology and Biostatistics, Texas A\&M University, USA.

${ }^{4}$ Department of Pharmaceutical Sciences, Universitá degli Studi di Milano, Italy

${ }^{5}$ Faculty of Public Health, Naresuan University, Thailand

${ }^{6}$ Department of Pharmacology and Therapeutics, Ahmadu Bello University, Nigeria

*Corrresponding author: yjamilu@abu.edu.ng
}

Received: April 11, 2020; revised: May 21, 2020; accepted: May 21, 2020.

\begin{abstract}
The prevalence of diabetes and its associated complications have continued to increase globally. Tight glycemic control has been one of the effective ways towards the management of diabetes and its complications. This study was conducted to investigate independent predictors of glycemic levels among patients with diabetes attending a diabetic clinic of a tertiary health care facility. More than half (54.2\%) of the 216 participants had good glycemic control. Participants with Body Mass Index (BMI) more than 25 had $79 \%$ lower odds of having controlled glycemic levels (95\% CI; 0.095, 0.479), compared to those with $\mathrm{BMI} \leq 25$. Patients on combination therapy have a significantly higher odds of having good glycemic control compared to those on monotherapy [AOR 3.43 (1.615, 7.302)]. Other identified significant predictors of glycemic control include multiple complications, retinopathy, ethnicity, and self-reported physical activity $(\mathrm{p}<0.05)$. Our findings demonstrated that ethnicity, BMI, physical activity, retinopathy, and having more than one complication were independently associated with good glycemic control levels.
\end{abstract}

Keywords: Antidiabetics, Diabetes, Diabetic complication, Glycemic control 


\section{Introduction}

Diabetes mellitus (DM) is a metabolic disorder that has been pandemic over decades. DM has been a public health problem not only in developed countries but also in developing ones including Nigeria. Its prevalence has been on a steady rise; over 151 million diagnosed in 2000, about 194 million in 2003, 246 million in 2006, 285 million in 2014 and 415 million in 2015 (Atlas, 2015; Rathmann and Giani, 2004). This trend has been projected to increase to 642 million by the year 2040 (Guariguata and Shaw, 2014; Wild and King, 2004). Overweight, urbanization and obesity have greatly contributed to the increase in the global prevalence of DM from 108 million in 1980 to 422 million in 2014 (WHO, 2006). Similar patterns were observed in Africa where the prevalence rose from 4 million in 1980 to 25 million in 2014 (WHO, 2016). Research findings demonstrate that changing demographic trends, unhealthy diets are additional important factors associated with an increase in the prevalence of DM in most countries (Beran and Yudkin, 2013; Guariguata and Shaw, 2014; Bell, 2014). Similarly, a nation-wide study revealed an increased prevalence of DM in Nigeria, with increasing complications and other burdens (Davies Adeloye, 2017). To curtail developing further complications, diet modification and exercise have been employed as the initial approach for diabetes patient management. Other non-pharmacological approaches have also been used, which are generally complemented with one or more oral hypoglycemic agents and/or insulin therapy (Cavaiola and Pettus, 2017). More importantly a closely monitoring of glycemic levels is essential to diabetes care and management towards prevention of treatment failure and boosting treatments success rates (LeRoith and Smith, 2013). Diabetes complications have been implicated as the most important risk factors for diabetes morbidity and mortality (Lloyd and Hopkinson, 2001; Stratton and Holman, 2000). Though complications could be attributed to treatment modality, patient characteristics, and duration of therapy, they usually arise due to poor glycemic control, inappropriate management approach or even improperly selected patients and treatment modalities. Good glycemic control prevents early onset and progression of complications (Group, 1998; Control and Group, 1993; Zimmet and Shaw, 2001) as well as improved quality of life (Valentine and Roze, 2006). On the other hand, poorly controlled glycemic level constitutes important threat to public health leading to early onset of diabetes complications, increase costs of treatments, mortality and reduced quality of life (Lloyd and Hopkinson, 2001; Stratton and Holman, 2000). Several studies have reported high proportions of patients with uncontrolled glycemic levels in the developing countries where resources are limited and the majority of patients in clinical care do not reach the optimal glycemic control (Kibirige and Lumu, 2017; Sobngwi and Ohwovoriole, 2012). However, studies investigating predictors of good glycemic control in Nigerian health care facilities are lacking. Therefore, this study aimed to investigate independent predictors of good glycemic control among diabetes patients attending Diabetic Clinics of the Ahmadu Bello University Teaching Hospital-Shika (ABUTH-Shika), a tertiary health facility in Northern Nigeria.

\section{Methods}

\subsection{Study population and design}

This retrospective cross-sectional study was conducted at the Ahmadu Bello University Teaching Hospital (ABUTH), using secondary data covering from January 2008 to December 
2008. As a teaching hospital, ABUTH is classified as a tertiary health institution located in Shika-Zaria city of Kaduna State, Nigeria. ABUTH serves as a teaching facility for students of Medicine, Pharmacy and Allied Health Sciences. It is located at the central region of Northern Nigeria, serving all the nineteen Northern States of Nigeria, some neighboring states, and countries. Northern Nigeria constitutes more than $50 \%$ of the Nigerian population, and the city of Zaria has a population of 975,153 (Commission, 2007). The study involved a retrospective review of the patientsâÁź drug prescriptions throughout the study period. The set inclusion criteria were; attended the diabetic clinic of the ABUTH within 2008, clinically established diagnosis of Diabetes Mellitus based on a fasting blood sugar level of $126 \mathrm{mg} / \mathrm{dL}$ $(7.0 \mathrm{mmol} / \mathrm{L})$ and above or 2 hours postprandial sugar level of $200 \mathrm{mg} / \mathrm{dL}(10.0 \mathrm{mmol} / \mathrm{L})$ and above, and receiving antidiabetic drugs singly or in combination. Participants that did not meet the set inclusion criteria were excluded from this study.

\subsection{Sample size}

The sample size was estimated based on the recommendation that a minimum of 5âĂş10 records per variable is required to obtain a sufficient sample size to provide confidence margin of error within 5-15\% of the estimated proportion with $95 \%$ confidence level (Gearing and Ickowicz, 2006; Worster and Haines, 2004; Peduzzi, 1996). The sample was made up of 216 patient records diagnosed with Type 2 diabetes mellitus accessible from the available records of patients that attended the clinic from January to December 2008 based on 95\% confidence level and 6.5\% margin of error (confidence intervals) https://www.surveysystem.com/sscalc.htm. The sampling was conveniently conducted based on the priori set inclusion criteria to arrive at the required sample size. Detailed sampling process is presented in Figure 1.

\subsection{Diagnostic criterion}

The diagnoses status of all participants was established by a physician based on the diabetes diagnostic criteria from the World Health Organization and American Diabetes Association diagnostic criteria for (American Diabetes 2009; WHO 2006). Diabetic clinical symptoms with fasting plasma glucose level at or above $126 \mathrm{mg} / \mathrm{dl}(7.0 \mathrm{mmol} / \mathrm{L})$, plasma glucose at or above $200 \mathrm{mg} / \mathrm{dl}(11.1 \mathrm{mmol} / \mathrm{L})$ two hours after a $75 \mathrm{~g}$ oral glucose load as in glucose tolerance test were employed criteria for diagnosis (WHO 2006). Other used criteria include symptoms of hyperglycemia and casual plasma glucose at or above $200 \mathrm{mg} / \mathrm{dl}$ (11.1 $\mathrm{mmol} / \mathrm{L}$ ) (American Diabetes 2009).

\subsection{Ethical consideration}

This study used de-identified data. Before the commencement of the study, ethical approval for the study protocol was granted by the Ethics Committee of the Ahmadu Bello University and the management of ABUTH-Shika-Zaria, Kaduna, Nigeria.

\subsection{Data collection}

Data were collected from the de-identified records of diabetes patients available from the Medical Outpatient Department (MOPD) and Library units of the ABTH for this study. The 


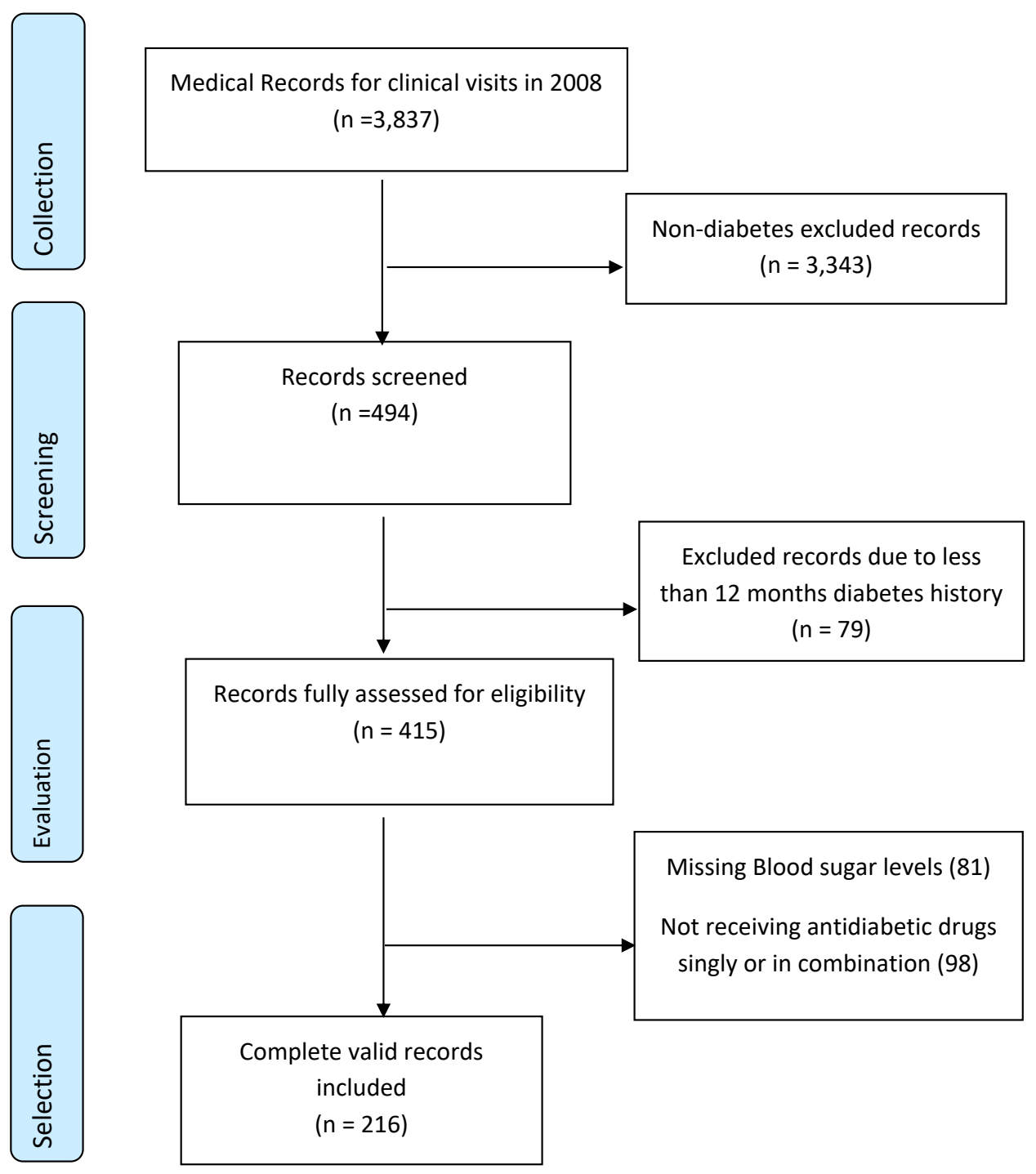

Figure 1 Sample size determination

Figure 1: An illustration of sampling process.

data were abstracted from the individual record for a period of one year, January 1, 2008, to December 31, 2008. We selected this period for data accessibility and feasibility reasons. Data collection form was designed, validated and used by the investigators. The recorded data included glycemic levels, demographics, diabetes complications, and prescribed drugs in the facility. The brand names of medicines in prescriptions were decoded to generic names 
of drugs and classified participants into monotherapy or combination therapy. The selected data included age, gender, BMI, anti-diabetic agent, and type of therapy (i.e., mono or combination therapy), ethnicity, physical activity status, duration of therapy, family history, hypertension and other diabetes complications. YA and GKM performed the data abstraction with support from a trained staff member of the medical record unit of ABUTH. Study variables Glycemic control level was the dependent categorical variable coded as controlled (good) or uncontrolled (poor). The glycemic control was measured by the Fasting Blood Sugar (FBS) and 2 hours postprandial sugar (2hr PPS) levels from average readings of the individual patient for at least 4 months period. The controlled (good) glycemic level was operationally defined as a fasting blood sugar level below $126 \mathrm{mg} / \mathrm{dL}(7.0 \mathrm{mmol} / \mathrm{L})$ or a 2 hours postprandial sugar level below 200mg/dL (10.0mmol/L) (American Diabetes 2009). While the uncontrolled (poor) glycemic level was defined as fasting blood sugar level of $126 \mathrm{mg} / \mathrm{dL}$ $(7.0 \mathrm{mmol} / \mathrm{L})$ and above or 2 hours postprandial sugar level of $200 \mathrm{mg} / \mathrm{dL}(10.0 \mathrm{mmol} / \mathrm{L})$ and above23. The FBG 2PPS were estimated using the glucose oxidase method. The independent variables include demographics (i.e. age, gender, self-reported physical activity, and ethnicity), family history of diabetes mellitus (DM) (yes/no), physical activity (active/inactive), body mass index (BMI) was classified into BMI $<25 \mathrm{~kg} / \mathrm{m}^{2}, \mathrm{BMI}=25-29.9 \mathrm{~kg} / \mathrm{m}^{2}$, and $\mathrm{BMI} \geq 30 \mathrm{~kg} / \mathrm{m}^{2}$ as normal, overweight, and obese groups, respectively. Diabetes complications such as hypertension defined based on systolic blood pressure (SBP) $\geq 140 \mathrm{mmHg}$ or diastolic blood pressure (DBP) $\geq 90 \mathrm{mmHg}$ or documented evidence of continued use of antihypertensive treatment. Other complications include stroke, retinopathy, nephropathy, diabetes foot ulcer, diabetic ketoacidosis, and amputation, duration of therapy, hospital admission, antidiabetic agent, and the number of complications.

\subsection{Data analysis}

The 12 months prevalence of controlled and uncontrolled glycemic levels among the participants was calculated. Bivariate analysis was used to investigate the association between glycemic control and individual predictor variable. Multiple logistic regression analysis was used to identify any independent associations. For building the logistic regression model, forward stepwise selection method was used, and specified the p-value for entry as 0.15 , while the p-value for removal was specified as 0.25 . More specifically, any variables whose test has a p-value less than 0.25 along with all variables of known clinical importance were subjected to the stepwise forward selection process as candidates for fitting a multivariable model. The variables considered in the stepwise selection method include Age, Sex, ethnicity, type of therapy, duration of therapy, number of complications (i.e. complications include stroke, retinopathy, nephropathy, diabetes foot ulcer, diabetic ketoacidosis, and amputation), family history, hospital admission, duration of therapy, antidiabetic agent, BMI, self-reported physical activity. This allowed us to explain the data easily by eliminating any redundant predictors that could undermine the accuracy of the estimates of interest. Odds ratios (ORs) and their corresponding 95\% confidence intervals (CIs) were calculated. We checked for possible interaction between independent variables and found none.The Hosmer-Lemeshow test was used to test the goodness of fit of our model by creating 10 groups. The approximate Hosmer-Lemeshow chi-square (8) statistic with 10 groups equals 6.81 , with $\mathrm{df}=10-2=8$, and $\mathrm{p}$-value $=0.5576$, indicating an adequate model fit. Significant variables included in the final model were the type of therapy, age, sex, ethnicity, number of complications, diabetes foot ulcer, BMI, physical activity, and retinopathy. All data analyses 
were performed using the Stata software (version 14.1; Stata Corp, College Station, TX). The results were considered significant when $\mathrm{p}$ values were $<0.05$.

\section{Results}

Based on the glycemic control status, $54.2 \%(n=117)$ of the study participants were classified as the controlled glycemic group, whereas $45.8 \%(n=99)$ as the uncontrolled glycemic group 1 (Table 1). While the vast majority of the controlled $(91.5 \%)$ and the uncontrolled (85.86\%) were 40 years and older, the average ages of the controlled and uncontrolled groups were $50.97 \pm 8.78$ and $53.34 \pm 10.38$ respectively (Table 1 ). More than half of the participants with controlled (59\%) and uncontrolled (56.4\%) glycemic level were females. Participants from the Hausa-Fulani ethnic background had a higher proportion (59\%) of people with uncontrolled glycemic level than Non-Hausa (41.4\%). Similarly, the proportion of participants with BMI $>25$ was higher among the uncontrolled (82\%) than the controlled group (56\%), $\mathrm{p}<0.0001$ (Table 1 ). The vast majority of the patients with a controlled glycemic level were on combination therapy $(78.63 \%)$ as against only $55 \%$ of the uncontrolled group. Fewer than a third (29\%) and almost a half $(46 \%)$ of the patients in the controlled and uncontrolled groups, respectively, had more than 4 years of treatment. Despite the prevalent family history of diabetes in both groups, most of the patients in both groups were self-reportedly inactive. Only half of the patients in the controlled group and about four-fifths of patients in the uncontrolled group had at least 2 diabetes complications. An overwhelming proportion of both groups had hypertension, with more hospital admissions among the uncontrolled group (31\%) than the controlled group (22\%). Nearly 3\% and $5 \%$ of patients in the controlled and uncontrolled groups, respectively, had retinopathy. Other complications such as diabetic ketoacidosis, diabetic foot ulcer (amputation), and stroke were more prevalent among the uncontrolled group. Surprisingly, nephropathy was more prevalent among patients with a controlled glycemic level (25\%) than the uncontrolled group (19\%).

The results for bivariate and multivariate logistic regression analysis of independent predictors of good glycemic control were presented in 2 . Unadjusted logistic regression analysis demonstrated that male participants were less likely to have good glycemic control, compared to female participants $0.91(0.527,1.558), \mathrm{p}=0.721$. The association was not significant even after adjusting for confounders in the final model. Based on the adjusted model, participants on combination therapy have significantly higher odds of good glycemic control, compared to monotherapy AOR $=3.43(1.615,7.302), \mathrm{p}=0.001$. Based on ethnicity, bivariate analysis demonstrates a significant association between ethnicity and blood glycemic levels. Moreover, the adjusted model showed that Non-Hausa/Fulani have 2.6 times higher odds of having controlled glycemic levels compared to Hausa-Fulani $(\mathrm{p}=0.008)$. The odds of having controlled glycemic levels $(<7 \mathrm{mmol} / \mathrm{L})$ was 2.61 higher among self-reported physically active participants (95\% CI; $1.136,5.985, \mathrm{p}=0.024)$, compared to the physically inactive participants. As opposed to participants without diabetic foot ulcers, those with diabetic foot ulcers were at 66\% lower odds of controlled glycemic level (95\% CI; 0.134, 0.840), $\mathrm{p}=0.020$. Participants with a BMI of more than 25 had $79 \%$ lower odds of having controlled blood glycemic level $(\mathrm{p}<0.001)$. Participants with more than one complication had $88 \%$ lower odds of having controlled blood glycemic levels, compared to those with one complication (95\% CI; 0.054, 0.278; $\mathrm{p}<0.001)$. When compared with participants without 
Table 1: Demographic characteristics of the study participants based on the glycemic control status.

\begin{tabular}{|c|c|c|c|}
\hline Covariates & Controlled n(\%) & Uncontrolled n(\%) & P-value + \\
\hline \multicolumn{4}{|l|}{ Age } \\
\hline$\leq 40$ years & $10(8.5)$ & $14(14.1)$ & 0.281 \\
\hline$\geq 40$ years & 107(91.5) & $85(85.9)$ & \\
\hline \multicolumn{4}{|l|}{ Gender } \\
\hline Male & $48(41.0)$ & $43(43.4)$ & 0.721 \\
\hline Female & $69(59.0)$ & $56(56.6)$ & \\
\hline \multicolumn{4}{|l|}{ Ethnicity } \\
\hline Hausa-Fulani & $52(44.4)$ & $58(58.6)$ & 0.469 \\
\hline Non-Hausa/Fulani & $62(54.4)$ & $41(41.4)$ & \\
\hline \multicolumn{4}{|l|}{ BMI $(\mathrm{kg} / \mathrm{m} 2)$} \\
\hline$\leq 25$ & $51(44.3)$ & $18(18.2)$ & 0.044 \\
\hline$>25$ & $64(55.7)$ & $81(81.8)$ & \\
\hline \multicolumn{4}{|l|}{ Therapy } \\
\hline Monotherapy & $25(21.4)$ & $44(44.9)$ & 0.019 \\
\hline Combo-therapy & $92(78.6)$ & $54(55.1)$ & \\
\hline \multicolumn{4}{|l|}{ During of Therapy } \\
\hline$\leq 4$ years & $83(70.9)$ & $54(54.5)$ & 0.015 \\
\hline$>4$ years & $34(29.1)$ & $45(45.5)$ & \\
\hline \multicolumn{4}{|l|}{ Physical Activity } \\
\hline Active & $34(29.1)$ & $20(20.2)$ & 0.052 \\
\hline Inactive & $82(70.9)$ & $77(77.8)$ & \\
\hline \multicolumn{4}{|l|}{ Family history of DM } \\
\hline Yes & $71(61.0)$ & $67(67.7)$ & 0.286 \\
\hline No & $46(39.0)$ & $32(32.3)$ & \\
\hline \multicolumn{4}{|l|}{ Complications } \\
\hline$\lesssim 2$ & $57(48.7)$ & $21(21.2)$ & 0.001 \\
\hline$\geq$ & $60(51.3)$ & $78(78.8)$ & \\
\hline Hypertension & $98(83.8)$ & $83(83.8)$ & 0.670 \\
\hline Hospital admission & $26(22.2)$ & $31(31.3)$ & 0.132 \\
\hline Retinopathy & $3(2.6)$ & $5(5.1)$ & 0.036 \\
\hline Nephropathy & $29(24.8)$ & $19(19.2)$ & 0.682 \\
\hline Diabetic ketoacidosis & $22(18.8)$ & $22(22.2)$ & 0.535 \\
\hline Diabetic footulcer & $11(9.4)$ & $22(22.2)$ & 0.012 \\
\hline Stroke & $5(3.42)$ & $4(4.04)$ & 0.932 \\
\hline Total & $117(54.2)$ & $99(445.8)$ & \\
\hline
\end{tabular}

Note: FBS, Fasting Blood Sugar; 2HRPP, 2 hours postprandial sugar test; DOT, Duration of Therapy; $\mathrm{SD}$, Standard deviation; BMI, Body Mass Index +, t-test;

complications, those with retinopathy had $99.9 \%$ lower odds of having controlled blood glycemic levels $(\mathrm{p}=0.006)$. 
Table 2: Demographic characteristics of the study participants based on the glycemic control status.

\begin{tabular}{|c|c|c|c|c|}
\hline Covariates & $\begin{array}{r}\text { Unadjusted } \\
\text { COR }(95 \% \mathrm{CI})\end{array}$ & \multicolumn{2}{|r|}{ Prediction Model 2} & P-value \\
\hline Type of therapy & & & & \\
\hline Monotherapy & 1.00(Reference) & & & \\
\hline Combination & $1.95(1.116,3.417)$ & $0.019 *$ & $3.43(1.615,7.302)$ & $0.001 *$ \\
\hline Gender & & & & \\
\hline Female & 1.00(Reference) & & & \\
\hline Male & $0.91(0.527,1.558)$ & 0.721 & $0.50(0.244,1.008)$ & 0.053 \\
\hline Ethnicity & & & & \\
\hline Hausa-Fulani & 1.00 (Reference) & & & \\
\hline $\begin{array}{l}\text { Non-Hausa/Fulani } \\
\mathrm{BMI}(\mathrm{kg} / \mathrm{m} 2)\end{array}$ & $1.69(0.979,2.905)$ & 0.060 & $2.62(1.291,5.321)$ & $0.008^{*}$ \\
\hline$\leq 25$ & 1.00(Reference) & & & \\
\hline$>25$ & $0.28(0.149,0.523)$ & $<0.001^{*}$ & $0.21(0.095,0.479)$ & $0.001^{* *}$ \\
\hline $\begin{array}{l}\text { Physical activity } \\
\text { inactive }\end{array}$ & 1.00(Reference) & & & \\
\hline $\begin{array}{l}\text { active } \\
\text { Complications }\end{array}$ & $1.94(0.993,3.805)$ & 0.052 & $2.61(1.136,5.985)$ & $0.024^{*}$ \\
\hline$\lesssim 1$ & 1.00(Reference) & & & \\
\hline$\geq 2$ & $0.28(0.155,0.518)$ & $<0.0001^{*}$ & $0.12(0.054,0.278)$ & $0.001 * *$ \\
\hline $\begin{array}{l}\text { Foot Ulcer } \\
\text { No }\end{array}$ & 1.00(Reference) & & & \\
\hline Yes & $0.38(0.177,0.806)$ & $0.012 *$ & $0.34(0.134,0.840)$ & $0.020 *$ \\
\hline Retinopathy & & & & \\
\hline No & 1.00(Reference) & & & \\
\hline Yes & $0.28(0.087,0.920)$ & $0.036 *$ & $0.10(0.019,0.511)$ & $0.006^{*}$ \\
\hline
\end{tabular}

*P-value less than 0.05; **P-value less than 0.001; COD, Crude Odds Ratio; AOR, Adjusted Odds ratio; Duration of Therapy; CI, Confidence Intervals

\section{Discussion}

The ultimate goal in diabetes mellitus management is centrally focused on achieving a controlled glycemic level, which is essential in preventing short-term and long-term diabetes complications. Moreover, the success of any Type 2 diabetes management largely depends on several factors, including pharmacotherapy and non-pharmacological approaches. From the present study, it can be deduced that more than half (54.2\%) of the total participants had controlled glycemic levels, while a significant portion of the participants $(45.8 \%)$ are classified as having uncontrolled glycemic levels. This finding is in contrast to the widely reported poor glycemic control among diabetes patients in Southern Nigeria, as supported by preceding literature. For instance, as high as $59.4 \%$ of poor glycemic control has been reported (Osuji and Odebunmi, 2013), 55\% (Ufuoma and Ngozi, 2016) and Fiseha and co-workers also reported an overwhelming $71 \%$ poor glycemic control among diabetes patients in a hospital-based cross-sectional study in North-eastern Ethiopia (Fiseha and Gebreweld, 2018). Similarly, in Asia, Li et al. reported inadequate glycemic control (50.3\%) among Type 2 diabetes patients attending tertiary healthcare facility in Ningbo, China (Li 
and Li, 2018). However, effective glycemic control among diabetes patients have been reported in Germany, and Japan, which were attributed to the influence of the socioeconomic status of the patients (Arai and Terauchi, 2008; Reisig and Group, 2007). The improved glycemic control observed in the present study could be related to study settings differentials and dynamics. Even though the setting of the present study was a tertiary referral teaching hospital, it is one of the largest healthcare facilities in Nigeria with a high capacity of healthcare personnel and domiciled within a semi-urban area. In addition, the city is surrounded by numerous tertiary educational institutions. Therefore, it is only plausible to assume that the majority of the patients attending the facility had high literacy levels which could have been advantageous in making informed decisions about treatment and management of the disease. Moreover, most of the diabetes patient there are receiving patientcentred management of their diabetes condition, with multisectoral approach from family doctors, pharmacists, nurses, nutritionist among others, translating into the high proportion of participants with controlled blood sugar levels. Moreover, evidence-based research has shown a cogent role of diabetes self-management education (DSME) as a fundamental element in the management of diabetes (Essien and Walley, 2013; Haas and Kolb, 2012). Indeed, a lack of knowledge about diabetes and its treatment modalities, especially the nonpharmacological aspects, have been attributed to low levels of glycemic control (Ahmad and Paraidathathu, 2014). The Non-Hausas were seemingly more likely to maintain a controlled glycemic level. This was not surprising given that ethnic background could be an important aspect of glycemic control as Nigeria is a multiethnic society shaped by numerous cultural norms and traditional practices. Further, it could be attributed to the different literacy levels among the ethnic groups as literacy rate among the Hausa-Fulanis was generally lower than other ethnic groups. It could also be attributable to the socioeconomic status which has been identified to contribute significantly in glycemic control imbalance (Reisig and Group, 2007). Expectedly, participants whose BMI were greater than 25 were less likely to have a controlled glycemic level. This is reasonable because having a blood glucose level above normal adds to the visceral mass which precipitates overweight and possibly obesity. The significant finding on the influence of BMI on glycemic control is in agreement with many findings in the literature (Ahmad and Paraidathathu, 2014; Arai and Terauchi, 2008; Essien and Walley, 2013). More so, several studies reported a direct link between obesity and its complications such as Type 2 diabetes (Lawlor and Smith, 2010; Steinberger and Sinaiko, 2005). Combination therapy was found to positively influence good glycemic control. This did not come as a surprise given that the overwhelming majority of the participants with controlled glycemic level and slightly higher than half of the uncontrolled glycemic group were on combination therapy. This is not a surprise as many studies have shown the effectiveness of combination therapy approach in the management of diabetes mellitus (Bell, 2013; Sekar and Vasanthi, 2019). This is due to the ability of the different pharmacological agents to act via different mechanisms of action in bringing down the blood sugar level to the normal range. An efficient glycemic control is expected to contribute tremendously in lowering the rate of complications in patients with diabetes mellitus. The chances of increased hospital stay, and developing other complications such as retinopathy, diabetes ketoacidosis, diabetes foot ulcers and amputation are higher among those with uncontrolled blood sugar levels. Perhaps, many studies have also demonstrated a clinical link between poor glycemic control and complications in diabetes patients (Laotaveerungrueng and Lertwattanarak, 2018; Morales-Alvarez and Rosas, 2019). 


\section{Conclusion}

This study demonstrates that antidiabetic regimens containing more than one drug, BMI, physical activity, retinopathy and having more than one complication were the significant independent predictors of having a controlled blood sugar. Therefore, putting a priority on the identified predictors in the management of diabetes would be effective towards optimization of blood glucose levels among diabetes patients, while keeping the whole diabetic management strategies in check. Limitations of the study Some important variables such as economic status, education status, medication adherence, and non-diabetic medication history were not available in the accessed data. The cross-sectional design used in the present study could not allow establishing temporality between the glycemic levels and the investigated predictors. Moreover, the small sample size may also pose certain limitations to the power of this study. Another important limitation of this study is the external validity. The findings of this study might not necessarily applicable to populations other than diabetic patients in a setting similar to the present study setting.

\section{Acknowledgments}

The authors are very thankful to Malam Abubakar of the Health Information Department (Health Record Office), all the participants and clinical Staff of the ABUTH, Zaria-Shika for their contribution towards successful completion of this study.

\section{Declarations}

Author Contribution: YA and JA designed the study and drafted the first version of the manuscript; AY and YS GMK conducted the data analysis. GMK, AY, YS and JY revised it critically for important intellectual content and approved the final version.

Funding: The study was not supported by any funding.

Conflict of interest: None declared.

Ethical approval: Ethical clearance for this study was taken from the Ahmadu Bello University and the management of ABUTH-Shika-Zaria, Kaduna, Nigeria as appropriate.

\section{References}

Ahmad N S IF, Paraidathathu T (2014). "Factors associated with good glycemic control among patients with type 2 diabetes mellitus." Journal of Diabetes Investigation, 5(5), 563-69. doi:10.1111/jdi.12175.

Arai K HKMITMMKTHKAYMMH, Terauchi Y (2008). "The status of glycemic control by general practitioners and specialists for diabetes in Japan: a cross-sectional survey of 15,652 patients with diabetes mellitus." Diabetes Res Clin Pract, 83(3), 397-401. doi:10.1016/j.diabres.2008.11.036.

Atlas D (2015). International diabetes federation: Diabetes Atlas. The Global Burden of Diabetes, 7 edition. International diabetes federation, Brussels, Belgium.

BRR Www.jBiomedAnalytics.org 
Bell D (2013). "Combine and conquer: advantages and disadvantages of fixeddose combination therapy." Diabetes, Obesity and Metabolism, 15(4), 291-300. doi:10.1111/dom.12015.

Bell D (2014). "Diabetes mellitus in Nigeria: The past, present and future." World J Diabetes, 5(6), 905-11. doi:10.4239/wjd.v5.i6.905.

Beran D, Yudkin JS (2013). "Diabetes care in sub-Saharan Africa." Diabetes, Obesity and Metabolism, 368(9548), 1689-1695. doi:10.1016/s0140-6736(06)69704-3.

Cavaiola TS, Pettus JH (2017). Management of type 2 diabetes: selecting amongst available pharmacological agents, volume Endotext [Internet]. MDText.com, Inc.

Commission NNP (2007). "Report of Nigeria's National Population Commission on the 2006 Census." Population and Development Review, 33(1), 206-210. URL http://www.jstor.org/ stable/25434601.

Control D, Group CTR (1993). "The effect of intensive treatment of diabetes on the development and progression of long-term complications in insulindependent diabetes mellitus." New England journal of medicine, 329(14), 977-986. doi:10.1056/NEJM199309303291401.

Davies Adeloye Janet O Ige AVANAEOAAAGO (2017). "Estimating the prevalence, hospitalisation and mortality from type 2 diabetes mellitus in Nigeria: a systematic review and meta-analysis." BMJ, 7(5), e015424. doi:10.1136/bmjopen-2016-015424.

Essien O OAUVEOHJP, Walley J (2013). "Intensive patient education improves glycaemic control in diabetes compared to conventional education: a randomised controlled trial in a Nigerian tertiary care hospital." PloS one, 12(1), e0168835. doi:10.1371/journal.pone.0168835.

Fiseha T AEKWAA, Gebreweld A (2018). "Factors associated with glycemic control among diabetic adult out-patients in Northeast Ethiopia." BMC research notes, 11(1), 316. doi:10.1186/s13104-018-3423-5.

Gearing R E MIABJ, Ickowicz A (2006). "A methodology for conducting retrospective chart review research in child and adolescent psychiatry." The JCACAP, 15(3), 126. doi:PMCID: PMC2277255 PMID: 18392182.

Group UPDS (1998). "Intensive blood-glucose control with sulphonylureas or insulin compared with conventional treatment and risk of complications in patients with type 2 diabetes (UKPDS 33)." The Lancet, 352(9131), 837-53. doi:https://doi.org/10.1016/S01406736(98)07019-6.

Guariguata L WDRHIBJLU, Shaw JE (2014). "Global estimates of diabetes prevalence for 2013 and projections for 2035." Diabetes Res Clin Pract, 103(2), 137-49. doi:10.1016/j.diabres.2013.11.002.

Haas L MMBJCCEDPELFEHLKD, Kolb L (2012). "National standards for diabetes self-management education and support." The Diabetes Educator, 15(4), 291-300. doi:https://doi.org/10.2337/dc12-1707. 
Kibirige D AGPKLKDS, Lumu W (2017). "Frequency and predictors of suboptimal glycemic control in an African diabetic population." Int $J$ Gen Med, 10, 33-38. doi:10.2147/ijgm.s124548.

Laotaveerungrueng N WSWT, Lertwattanarak R (2018). "Prevalence of Chronic Microvascular Complications and Diabetic Foot Problems in Patients with Diabetes Mellitus at Siriraj Hospital." Journal of the Medical Association of Thailand, 101(10), 1349-55. doi:http://www.jmatonline.com/index.php/jmat/article/view/8972\#.

Lawlor D A BLLJTKHLDFACLWPNAR, Smith GD (2010). "Association between general and central adiposity in childhood, and change in these, with cardiovascular risk factors in adolescence: prospective cohort study." Bmj, 341(25), c6224. doi:10.1136/bmj.c6224.

LeRoith D, Smith DO (2013). "Monitoring glycemic control: the cornerstone of diabetes care." Clin Ther, 27(10), 1489-99. doi:10.1016/j.clinthera.2005.10.010.

Li J CKXMCYHFCJ, Li L (2018). "Glycaemic control in type 2 diabetes patients and its predictors: a retrospective database study at a tertiary care diabetes centre in Ningbo, China." BMJ Open, 8(3), e019697. doi:10.1136/bmjopen-2017-019697.

Lloyd A SW, Hopkinson P (2001). "Impact of longâĂŘterm complications on quality of life in patients with type 2 diabetes not using insulin." Value in Health, 4(5), 392-400. doi:10.1046/j.1524-4733.2001.45029.x.

Morales-Alvarez M C GDGMFA, Rosas SE (2019). "Renal Function Decline in Latinos with Type 2 Diabetes." Kidney International Reports, 9(4), 1230-1234. doi:https://doi.org/10.1016/j.ekir.2019.05.012.

Osuji N A OOSMSOSPTEAO, Odebunmi OO (2013). "Relationship between glycemic control and perceived family support among people with type 2 diabetes mellitus seen in a rich kinship network in Southwest Nigeria." Family Medicine and Community Health, 6(4), 168-77. doi:https://doi.org/10.15212/FMCH.2018.0115.

Peduzzi P CJKEHTRFAR (1996). "A simulation study of the number of events per variable in logistic regression analysis." Journal of clinical epidemiology, 49(12), 1373-1379. doi:https://doi.org/10.1016/s0895-4356(96)00236-3.

Rathmann W, Giani G (2004). "Global prevalence of diabetes: estimates for the year 2000 and projections for 2030." Diabetes Care, 27(10), 2568-2569. doi:10.2337/diacare.27.10.2568.

Reisig V RPDARWMA, Group KS (2007). "Social inequalities and outcomes in type 2 diabetes in the German region of Augsburg. A cross-sectional survey." International Journal of Public Health, 52(3), 158-65. doi:10.1007/s00038-007-5077-2.

Sekar V MSMRNP, Vasanthi HR (2019). "Antidiabetic effect of mangiferin in combination with oral hypoglycemic agents metformin and gliclazide." Annals of clinical biochemistry, 59, 152901. doi:10.1016/j.phymed.2019.152901.

Sobngwi E NMMBKARKLNEWDSNMJC, Ohwovoriole AE (2012). "Type 2 diabetes control and complications in specialised diabetes care centres of six sub-Saharan African countries: the Diabcare Africa study." Diabetes Res Clin Pract, 95(1), 30-36. doi:10.1016/j.diabres.2011.10.018.

BRF Www.jBiomedAnalytics.org 
Steinberger J JJDRRSMAHC, Sinaiko AR (2005). "Comparison of body fatness measurements by BMI and skinfolds vs dual energy X-ray absorptiometry and their relation to cardiovascular risk factors in adolescents." International journal of obesity, 29(11), 1346. doi:10.1038/sj.ijo.0803026.

Stratton I M AAINHAWMDRMSECCAHDTRC, Holman RR (2000). "Association of glycaemia with macrovascular and microvascular complications of type 2 diabetes (UKPDS 35): prospective observational study." BMJ, 321(7258), 405-412. doi:10.1136/bmj.321.7258.405.

Ufuoma C GYDKAD, Ngozi JC (2016). "Determinants of glycemic control among persons with type 2 diabetes mellitus in Niger Delta." Sahel Medical Journal, 19(4), 190. doi:10.4103/1118-8561.196361.

Valentine W J PAJNLCD, Roze S (2006). "Improving life expectancy and decreasing the incidence of complications associated with type 2 diabetes: a modelling study of HbA1c targets." Int J Clin Pract, 60(9), 1138-45. doi:10.1111/j.1742-1241.2006.01102.x.

WHO (2006). "Definition and diagnosis of diabetes mellitus and intermediate hyperglycemia: report of a WHO/IDF consultation." 27. URL Availablefrom:https://www.who. int/diabetes/publications/diagnosis_diabetes2006/en/.

WHO WHO (2016). "World Health Organisation. Global report on diabetes." URL Availablefrom:www.who.int/diabetes/global-report.

Wild S RGGASR, King H (2004). "Global prevalence of diabetes: estimates for the year 2000 and projections for 2030." Diabetes Care, 27(5), 1047-53. doi:10.2337/diacare.27.5.1047.

Worster A, Haines T (2004). "Advanced statistics: Understanding Medical Record Review (MRR) Studies." Academic Emergency Medicine, 11(2), 187-192. doi:10.1111/j.15532712.2004.tb01433.x.

Zimmet P AKGMM, Shaw J (2001). "Global and societal implications of the diabetes epidemic." Nature, 414(6865), 782-787. doi:10.1038/414782a. 